\title{
ZKAYA, CORPO [NEGRO] E MODA ATIVISTA EM SANTA CATARINA
}

\section{ZKAYA, [BLACK] BODY AND ACTIVIST FASHION IN SANTA CATARINA}

\author{
Verdi Lazaro Alves Vilela \\ Mestrando em Moda pela Universidade do Estado de Santa Catarina (UDESC) - \\ lazvilela@gmail.com - orcid.org/0000-0002-8398-7589 \\ Daniela Novelli \\ Doutora em Ciências Humanas pela Universidade Federal de Santa Catarina (UFSC)- \\ daniela.novelli@udesc.br - orcid.org/0000-0001-6981-8933 \\ Lucas da Rosa \\ Doutor em Design pela Pontifícia Universidade Católica do Rio de Janeiro (PUC-Rio)- \\ darosa.lucas@gmail.com - orcid.org/0000-0002-8429-2754 \\ Icléia Silveira \\ Doutora em Design pela Pontifícia Universidade Católica do Rio de Janeiro (PUC-Rio)) - \\ icleiasilveira@gmail.com - orcid.org/0000-0003-4493-9768
}

\section{Resumo}

O presente artigo tem como objetivo identificar ações de engajamento estético-político da marca catarinense Zkaya voltadas para a valorização das subjetividades de identidades negras, no contexto do ativismo e da moda Afro-brasileira no cenário contemporâneo. Trata-se de uma pesquisa básica, qualitativa e descritiva, cujo levantamento bibliográfico permitiu construir o embasamento teórico, que discute primeiramente como operam as estruturas de poder sobre o corpo [negro], como a moda tem um papel fundamental em sua docilização e, contudo, aponta para o fato de que onde há poder, existe resistência; em seguida, apresenta um comparativo de como algumas marcas ativistas brasileiras estão resistindo ao sistema dominante, para finalmente apresentar os resultados de dados coletados por meio de entrevista e acesso a site e redes sociais da principal marca em questão, de modo a tornar possível a afirmação de que a Zkaya é uma marca ativista que ressignifica a moda e valoriza aspectos históricos e socioculturais associados às subjetividades das identidades negras.

Palavras-chave: Moda - Atividades políticas; Negros - Identidade racial; Ativistas pelos direitos humanos Santa Catarina; Relações étnicas.

\begin{abstract}
This article aims to identify action of aesthetic-politic engagement of Zkaya a South Brazilian brand turn to enrich subjectivities of black identities in the context of activism and Afro-Brazilian fashion contemporary scenario. It is a basic research, qualitative and descriptive, whose bibliographic research allowed to build the treoretical basis, who debate at first on how the power structures operate over the [black] body, how the fashion has a fundamental role on its "docilization" and, nevertheless, point to the fact that where resides power, resides resistence; In the following, shows a comparative of how Brazilian activist brands are defying the dominant system, to finally presente the results of collected data though interviews, brand's website and social media, so as to make possible the affirmation that Zkaya is an activist brand that gives new meaning to fashion and values the social-cultural and historical aspects associated to subjectivities of black identities.
\end{abstract}

Keywords: Fashion - Political activity; Blacks - Race identity; Human rights workers - Santa Catarina; Ethnic relation. 


\section{INTRODUÇÃO}

Historicamente, a moda ocidental europeia traz consigo todo um sistema de regulação de corpos, que teve suas origens bem no centro das aparências aristocráticas das sociedades de corte do Renascimento (MICHETTI, 2012; LIPOVETSKY, 1987), em um primeiro período de emergência na Era Moderna. Mais tarde, no contexto da modernidade europeia do século XIX, a globalização contemporânea da moda (MICHETTI, 2012) acentuou a marginalização de determinadas identidades, sobretudo aquelas associadas a corpos negros, inclusive no Brasil.

Entretanto, após tantos séculos de hegemonia cultural branca na moda ocidental, percebese que esta última começa a testemunhar, a partir da segunda metade do século XX, o protagonismo do corpo e o investimento na imagem de si, impulsionando ao mesmo tempo o surgimento de marcas brasileiras que se comprometem com a valorização da expressão dessas subjetividades excluídas e é justamente da análise qualitativa e descritiva do contexto brasileiro dessas marcas que também discorre o presente artigo.

Trata-se de uma pesquisa que teve como objetivo identificar ações de engajamento estético-político da marca catarinense Zkaya voltadas para a valorização das subjetividades de identidades negras, no contexto do ativismo e da moda Afro-brasileira no cenário contemporâneo, bem como para a ressignificação do sistema sociocultural e econômico hegemônico da moda. Para tanto, responde primeiro como operam as estruturas de poder sobre o corpo [negro] ${ }^{1}$ e como a moda tem um papel fundamental em sua docilização, ao mesmo tempo em que identifica possibilidades concretas e positivas de (r)existência deste mesmo corpo e de suas subjetividades por meio de discursos ativistas.

Apesar do crescente avanço do neoliberalismo mundial no cenário político brasileiro contemporâneo, o mercado da moda passa por um momento de transformação em direção à maior valorização da expressão de subjetividades de indivíduos historicamente excluídos do seu sistema até bem pouco tempo atrás e, desta forma, torna-se relevante trazer para o campo da Moda

\footnotetext{
${ }^{1}$ Utiliza-se o termo "negro" entre colchetes no texto em todos os sentidos nos quais pretende-se chamar atenção para a (in)visibilidade a ele socioculturalmente atribuída no contexto de sociedades ocidentais modernas e contemporâneas historicamente pautadas na hegemonia branca - entendendo a branquidade não apenas como cor da pele, mas um lugar de vantagem estrutural de privilégio racial branco.
} 
paradigmas mais pertinentes à reflexão. Trata-se portanto de um tema academicamente pouco discutido na área, que evidência por sua vez uma importante preocupação sobre mecanismos de controle, seja por meio da (re)produção de subjetividades ou da exploração social do trabalho.

Diante do exposto, para alcançar o objetivo proposto, este estudo se classifica como pesquisa básica, qualitativa e descritiva. Os procedimentos técnicos para elaborar o embasamento teórico tiveram como base fontes bibliográficas, em especial de livros, artigos, teses e dissertações, sendo os dados coletados ainda por meio de entrevista e acesso a site e redes sociais de marcas ativistas nacionais, em especial da marca Afro-brasileira Zkaya, do estado de Santa Catarina.

Assim, esse artigo aborda no primeiro tópico “Moda, Corpo[Negro] e a política das diferenças" uma importante contextualização sobre mudanças socioculturais referentes ao sistema de regulação dos corpos legitimado pela moda a partir da segunda metade do século XX (LIPOVETSKY, 1987), incluindo a questão da hipervalorizarão do corpo (MESQUITA; CASTILHO, 2012), pois parecem ser elementos-chave para a compreensão das visões de Katz (2012) e Aires (2019) sobre como a moda tem um papel biopolítico. Entretanto, sendo a questão racial o fio condutor da pesquisa, fez-se necessária a abordagem teórica sobre a política das diferenças (HALL, 2013).

O segundo tópico, "Ativismo e moda Afro-brasileira no cenário contemporâneo", apresenta como algumas marcas Afro-brasileiras - rede Kilofé, LAB, Isaac Silva e Carol Barreto - têm desenvolvido uma moda ativista no país, por meio de um breve estudo sobre aspectos históricos, socioculturais, estéticos e políticos por elas agenciados no cenário atual da moda, a partir de suas produções visuais e discursivas. E questiona: pode a moda auxiliar na desconstrução das estruturas de poder brancas e eurocêntricas? Ou ainda, como a moda estaria auxiliando na desconstrução de tais estruturas no século XXI?

A partir dessas respostas são apresentadas no último tópico, "Zkaya e a arte de (re)existir", análises qualitativas das ações de engajamento estético-político da marca, por meio dedutivo/comparativo, a partir das quais foi possível afirmar que a Zkaya é uma marca ativista que ressignifica a moda e valoriza aspectos históricos e socioculturais associados às subjetividades das identidades negras. 


\section{MODA, CORPO [NEGRO] E A POLÍTICA DAS DIFERENÇAS}

Como apontado na Introdução do artigo, para se compreender como a moda ocidental moderna determinou historicamente a exclusão de determinados corpos, faz-se necessário olhar para o passado, incluindo algumas temporalidades - a emergência da moda aristocrática no Renascimento (MICHETTI, 2012; LIPOVETSKY, 1987), sua posterior globalização por meio da construção de uma pretensa universalidade de condições materiais e culturais necessárias para formar a "modernidade europeia" do século XIX tendo Paris como epicentro e seus desdobramentos no século subsequente, a partir dos quais questões relacionadas ao corpo e à aparência física ganharam centralidade e, ao mesmo tempo, abriram as portas para questionamentos a respeito do lugar do corpo negro na moda contemporânea do século XXI.

É importante salientar que a moda como sintoma da modernidade do século XIX foi historicamente construída para a atender à pretensa universalidade de condições materiais e culturais necessárias para formar tal "modernidade europeia" branca, apresentando-se nesse contexto como um importante fenômeno de regulação social ${ }^{2}$ (LIPOVETSKY, 1987). Para Crane (2006) a classe operária, por mais que tentasse, jamais alcançaria o amplo guarda-roupa da classe média burguesa em ascensão; deste modo, as diferenças sociais nas sociedades francesas, norte americanas e inglesas da época estavam atravessadas por marcadores de classe e gênero.

A roupa era notavelmente um divisor de classes sociais para mulheres e homens; as mulheres de classes altas que não precisavam trabalhar fora de casa tinham esses papéis sociais refletidos nas roupas, que, além de ornamentadas, também não eram práticas; já as mulheres casadas de classe média copiavam as roupas das mulheres de classes mais altas, embora com menos recursos; e, quanto às mulheres de classes operárias, pouco se sabe sobre elas, como atesta Crane (2006), afirmando entretanto que era comum terem o orçamento de roupas menor do que de seus maridos.

\footnotetext{
2 Por outro lado, entende-se a importância de liberar a própria ideia de moda do enquadramento teórico da modernidade ocidental, pois novos estudos criticam a separação alegadamente hierárquica entre "história da moda" e "história do costume" (MICHETTI, 2012) e, sob este prisma, acredita-se que esse artigo contribua, mesmo que de forma embrionária, para a formação de uma perspectiva decolonial e/ou pós-colonial da moda contemporânea.
} 
Compreende-se, portanto, a moda no século XIX como uma ferramenta de classificação social. Aires (2019) ressalta a existência de políticas de normalização estruturadas para legitimar grupos específicos: homens brancos, heterossexuais e europeus, de modo a tornar anormais aqueles cujos corpos se diferenciavam dessas regras sociais, culminando tal normalização justamente na temporalidade da globalização da moda contemporânea, na segunda metade do século XIX, em uma sociedade altamente classista.

A imbricação da biopolítica e do estabelecimento da moda no sentido que se conhece nas sociedades ocidentais contemporâneas desencadeou novos mecanismos de controle. Nesse período identifica-se a ação da biopolítica, "cujas técnicas disciplinares se dirigem ao corpo da população" (AIRES, 2019, p, 76), trazendo mudanças também para o campo da moda, em um conjunto específico de aspectos históricos e socioculturais do período, que ganha sentido moderno, segundo Lipovetsky (1987).

Segundo Aires (2019), existe uma "anatomopolítica", a ação de uma anatomia política diretamente sobre o corpo, ou seja, naquilo que o indivíduo tem de mais íntimo, e então "a biopolítica toma, por sua vez, como objeto de sua intervenção a espécie humana, a própria vida dos indivíduos" (AIRES, 2019, p. 77). Embora esta última volte o seu olhar para o corpo gordo na moda, tal anatomia política pode também ser observada sobre o corpo negro. A mesma autora também corrobora com a estreita relação entre moda e biopolítica, sobretudo sob a ótica de Michel Foucault, que observou a manifestação de métodos disciplinares sobre o corpo não apenas para aumentar suas habilidades, mas para tornar esse mecanismo obediente, útil, uma anatomia política, que se tornou uma mecânica de poder; e, ainda, a construção do anormal para favorecer a sociedade moderna capitalista, sobretudo com valores morais e sociais:

Foucault também analisa como vai se constituindo a figura do anormal. No período entre o século XVI e o século XIX, o autor observa preocupação com aqueles que, por algum motivo, tinham de ser classificados e localizados para melhor estruturação e andamento da sociedade moderna capitalista que se formava, cujos contornos eram delimitados pelos valores morais e sociais (AIRES, 2019, p. 76).

Se, para Aires (2009, p. 11), a moda também "tornou-se um fenômeno relacionado à construção e expressão da identidade do sujeito, correspondendo aos valores que ele deseja 'externar' por meio de sua aparência”, é ela a razão dos indivíduos buscarem semelhança com aqueles que eles acreditam serem superiores - os "normais" já mencionados por Foucault neste 
texto. Lipovetsky (1987, p. 35) se mostra ainda mais sensível e crítico a respeito da moda, ao considerá-la um "sistema original de regulação e de pressão sociais: suas mudanças apresentam um caráter constrangedor, são acompanhadas do "dever" de adoção e de assimilação, impõem-se mais ou menos obrigatoriamente a um meio social determinado".

Mas a moda que, para Lipovetsky, é efêmera e território de controle, poderia ser um campo de luta das identidades "anormais"? Como uma grande provocação, esta questão coloca em pauta o paradoxo do corpo fortalecido versus fragilizado de Mesquita e Castilho (2012). Para estas últimas, o início do século XX trouxe mudanças paradigmáticas em esferas políticas, econômicas, culturais e científicas, que por sua vez modificaram os modos de existir no mundo. Consequentemente, no decorrer deste século, como apontam as mesmas autoras, o corpo torna-se terreno de cruzamento dessas instâncias. Assim:

A ciência, tecnologia, o design, a moda, as artes e inúmeros outros setores produtivos, cujas políticas e economias são atravessadas por investimentos tão complexos quanto simplificadores, se instalaram nos entrelaçamentos entre a natureza orgânica, biológica e a cultura do corpo (MESQUITA; CASTILHO, 2012, p. 7).

A partir dos anos 1950 o corpo se torna protagonista, numa "etapa histórica na qual se apresenta como portador-vetor-expositor nos mais intensos paradoxos [...] tão fortalecido quanto fragilizado, tão famoso quanto esquecido [...]" (MESQUITA; CASTILHO, 2012, p. 8). Para as autoras, diferentemente de outros momentos históricos, nos quais as variáveis que integravam a "sensação de si" não se concentravam nas dimensões físicas, emergem no contemporâneo inúmeros investimentos na construção da própria imagem com o intuito de expressar a ordem de uma sensação de si, oscilando em identidades móveis e metamorfose antes (MESQUITA; CASTILHO, 2012).

Diante dessa nova perspectiva, valida-se a superexposição do corpo branco e a moda do século XX ganha ainda maior sentido biopolítico "quando publiciza um tipo de corpo que colabora com a domesticação da nossa percepção, alimentando-a somente com aspectos mais aparentes da sua visibilidade" (KATZ, 2012, p. 17). Mas a hipervisibilidade contemporânea do corpo branco domesticado acaba revelando a invisibilidade do corpo [negro]. Nesse sentido, no que diz respeito às invisibilidades do corpo negro no Brasil, considera-se os estudos de Buitoni (2009) sobre a imprensa brasileira, que validam as palavras de Katz (2012): 
A mulher branca, sorridente, é rótulo e marca do produto chamado imprensa feminina. Verdadeira mulher de papel que conserva fracos pontos de contato com a realidade. Num país de mestiços, a negra raramente surge em revistas femininas, a não ser como manequim exótico [...]. A mulher brasileira mesmo não frequenta as páginas da imprensa a ela dedicada (NOVELLI, 2014, p. 80 apud BUITONI, 2009, p. 209).

O fato se torna mais preocupante diante de todo o poder simbólico da influência midiática que tais revistas exerciam e ainda exercem sobre a sociedade brasileira. Para Novelli (2014), revistas - sobretudo as de moda - foram fundamentais para o mercado capitalista, para além de responsáveis pelo progresso da publicidade, moldaram as concepções de luxo. Assim, "o luxo e o lazer foram sendo gradativamente associados à ideia de revista no século XX e a imprensa elegeu a revista como seu veículo por excelência" (NOVELLI, 2014, p. 80), fabricando e vendendo identidades.

Para se pensar a função da moda na construção identitária, sobretudo das identidades do corpo [negro], é importante salientar a existência de uma "política das diferenças" (HALL, 2013, tradução nossa). De imediato descarta-se a possibilidade da diferenciação da raça estar no seu caráter fenotípico, estando pautada no aspecto cultural e discursivo, dado que Stuart Hall aponta que as considerações de raça como variações fenotípicas estão sendo cada vez mais consideradas racistas. Mesmo características fenotípicas estão relacionadas também ao ambiente físico e social, construídas contextual e discursivamente, sendo "flutuantes" ao desafiarem e desequilibrarem "os pressupostos do senso comum ou das maneiras cotidianas de falar da raça e de lhe dar sentido nas sociedades contemporâneas" (HALL, 2013, p. 95, tradução nossa).

Almeida (2019) concorda de certa forma com essa visão, ao afirmar que não existe nada de natural que corresponde com a raça:

No século $X X$, parte da antropologia constituiu-se a partir do esforço de demonstrar a autonomia das culturas e a inexistência de determinações biológicas ou culturais capazes de hierarquizar a moral, a cultura, a religião e os sistemas políticos. A constatação é a de que não há nada na realidade natural que corresponda ao conceito de raça (ALMEIDA, 2019, p. 22).

Desta maneira, fazendo um comparativo com o genocídio da Alemanha nazista, Almeida (2019) conclui que a raça é um elemento essencialmente político, sem nenhum sentido no meio socioantropológico. Novelli (2014) enfatiza que é possível validar a raça como linguagem pelo fato 
de seus significantes se referenciarem no eixo cultural, em práticas que consistem em "produzir sentidos", questionando:

Se existe sempre uma espécie de deslizamento [glissement], uma margem que não se encarna adequadamente na linguagem e na significação, por que vemos tão claramente os efeitos da raça como uma "realidade"? O que deixou traços de violência e de discriminação racial na história moderna e deixa ainda hoje é bem um significante, um discurso. Para entender a complexidade do funcionamento de sistemas de classificação e diferenciação racial é preciso considerá-lo não somente do ponto de vista realista e textual, mas discursivo (NOVELLI, 2014, p. 46).

Apontamentos que revelam o quanto a política advém de uma representação conflitante, de processos de mediação precários e instáveis, sem uma significação fixada, entretanto sempre diferenciada (HALL, 2013, tradução nossa), seguindo uma perspectiva que remete à questão da representação como diferença, pois trata-se de sistemas discursivos, como mencionado anteriormente. Deste modo, Hall (2013) considera a diferença como construtora social e propõe ainda outro termo para a compreensão da política das diferenças e mencionado pela autora - a articulação. Trata-se mais especificamente de:

[...] um meio de compreender como elementos ideológicos chegam, em certas condições, a formar um conjunto coerente em um discurso, bem como um meio de se interrogar sobre a maneira pela qual eles são ou não articulados a conjunturas específicas e a certos sujeitos políticos (HALL, 2013, p. 11, tradução nossa).

Compreender o conceito de articulação torna possível compreender que "a política das diferenças constitui uma prática do sujeito, que permite a articulação de uma identidade como posição reflexiva de enunciação e de ação" (HALL, 2013 apud NOVELLI, 2014, p. 47). No caso da racialização do povo negro, o que os diferencia historicamente dos brancos é uma construção social cristalizada, pautada na hierarquização de raças às custas de muitas lutas simbólicas identitárias. E, nesse sentido:

[...] raça é um conceito cujo significado só pode ser recolhido em perspectiva relacional. Ou seja, raça não é uma fantasmagoria, um delírio ou uma criação da cabeça de pessoas malintencionadas. É uma relação social, o que significa dizer que a raça se manifesta em atos concretos ocorridos no interior de uma estrutura social marcada por conflitos e antagonismos (ALMEIDA, 2019, p. 37).

A política das diferenças é um fator de construção social, ou seja, uma criação assistida por conflitos dos quais possibilitaram hierarquização racial. Não existe nada de natural no conceito de raça, por isso torna-se necessário entender a conexão entre a moda hegemônica da modernidade e a biopolítica; ambas aparecem com os mesmos ideais, voltados para legitimar o poder de homens, 
brancos, europeus e, assim, excluir por tanto tempo as pessoas negras. Paradoxalmente, essa mesma moda que Lipovetsky (1987) considera como efêmera e campo de controle social, é vista por autores como Aires (2019), Mesquita e Castilho (2012) como fator determinante na construção e na expressão de identidades.

Diante disso, reflete-se se a seguir a moda contemporânea enquanto um campo possível de ativismo de grupos minorizados, mais especificamente grupos negros. Foucault (1988) já dizia que onde há poder, existe resistência! E, desta forma, como atualmente algumas marcas Afrobrasileiras estariam resistindo ao sistema racial dominante.

\section{ATIVISMO E MODA AFRO-BRASILEIRA NO CENÁRIO CONTEMPORÂNEO}

Antes de abordar o cenário ativista de moda Afro-brasileira, apresenta-se o que está sendo chamado de ativismo, ou o que estaria sendo visto como ativismo no design e na moda; e, a partir da compreensão desses conceitos, aborda-se o que está se chamando de moda Afro-brasileira.

Para Bush (2017), o ativismo pode abranger um envolvimento político vigoroso e manobras operacionais civis, uma forma de abordar questões políticas fugindo da burocracia, completa que em uma democracia o ativismo significa ações para além do ato de votar, como: manifestações, protestos, ocupações e engajamento midiático, entre outros, conclui então que ativismo é desafiar consensos burocráticos. O mesmo autor ressalta que o ativismo no design propõe novos horizontes para a vida cotidiana e:

[...] é uma prática de engajamento, muitas vezes colaborativo e com senso de urgência, que assume a construção de novos meios pelos quais podemos atravessar o território fora dos caminhos designados. Trata-se de integração de novas redes, conectando práticas e dando novos sentidos ao mundo [...] (BUSH, 2017, p. 1).

Destaca-se a urgência de práticas ativistas, visto que para Almeida (2019) o racismo só pode ser combatido com a implementação de práticas antirracistas efetivas. Destaca-se também a necessidade de trilhar novos caminhos diferentes dos já designados e a interação de novas redes, tais destaques se validaram ao decorrer deste tópico. Assim, como estariam então as marcas Afrobrasileiras trabalhando o ativismo? Ou melhor, primeiramente, o que significa moda Afrobrasileira? 
Com base nos dados do relatório Sistema de Inteligência Setorial do Sebrae de Santa Catarina (SIS, 2016), a moda africana está cada vez mais inserida no vestuário Brasileiro, caracterizada por combinações de cores, texturas, estampas marcantes, e peças como: turbantes, colares de contas, batas e túnicas; seu público-alvo se apropria dela como uma maneira de revelar sua identidade cultural, ou também apenas para se sentir na moda. A cultura Afro é muito rica e seu vestuário pode revelar, hábitos, ancestralidade, danças, músicas e religiosidade. Para além de elementos africano, também pode ser incluído na criação de peças elementos Brasileiros e/ou Norte-Americanos. Carregar elementos africanos não quer dizer que essas peças sejam destinadas apenas para o público negro (SIS, 2016).

\begin{abstract}
A moda afro-brasileira destaca-se pelas estampas que valorizam as mulheres negras, pela utilização de formas geométricas, pelo uso de peles, fibras, aplicações, máscaras e fitas de poliamida, pedras, símbolos do candomblé, grafite e hip-hop. Entre as técnicas utilizadas sobressaem o macramé (roupas feitas manualmente, utilizando trançados e amarrações) e a moulage (roupas feitas com os tecidos diretamente no corpo) (SIS, 2016, p. 2).
\end{abstract}

Nota-se, então, que a moda Afro-brasileira é muito vasta e mescla elementos tanto da África como do Brasil, e o segmento vem crescendo no Brasil. Segundo dados da pesquisa do Instituto Brasileiro da qualidade e produtividade (IBQP), Sebrae e GEM 2019, apresentados pela Agência Sebrae de Notícias (ASN, 2020), a taxa de empreendedores pretos e pardos é maior do que a de brancos, pretos e pardos representam 39\% dos empreendedores, sendo $23,1 \%$ empreendedores iniciais, $15,7 \%$ de novos empreenderes, $8,1 \%$ de nascentes e $16,5 \%$ de empreendedores estabelecidos pardos ou pretos. Enquanto os empreendedores brancos representam respectivamente: $37,8 \%, 23,6 \%, 16,1 \%, 7,9 \%$ e 15,2\%. Entretanto, outros dados são preocupantes, apontados pela mesma fonte, e se referem a $27,1 \%$ dos empreenderes negros empreendem um negócio por necessidade, falta de emprego, e apenas 1,3\% dizem que empreendem para fazer a diferença no mundo (ASN, 2020); tais dados derrubam a "romantização" do empreendedorismo por ativismo, apontando o empreendedorismo por necessidade em um sistema estruturalmente racista.

Se, por um lado, o ideal hegemônico de corpo legitimado pela moda até muito pouco tempo classifica e diferencia corpos fora da norma, por outro a moda contemporânea do século XXI vem se mostrando como um terreno fértil de contestações sociais, estéticas e políticas - por meio de marcas que se comunicam de forma "reversa" aos padrões hegemônicos para dar visibilidade a 
identidades até então excluídas, ou ainda propondo novas condições de trabalho como opositoras ao fast-fashion ${ }^{3}$. Desta forma, como estariam algumas marcas brasileiras trabalhando essas ressignificações?

Santos (2019) destaca a rede Kilofé de economia de negros e negras no Ceará, que surge do desejo de fazer a ponte entre afrodescendentes e suas ancestralidades. Bernardo, coordenador da rede, aponta que mesmo depois das políticas públicas de igualdade racial terem sido implantadas em 2006, microempreendedores negros ainda não possuem os mesmos apoios em economias dominadas por brancos na sociedade brasileira; a rede Kilofé conta com aproximadamente 100 empreendedores negros e negras (CARVALHO, 2016 apud SANTOS, 2019).

Dentre essas marcas, a Bitten produz camisetas que ilustram o fortalecimento da mulher preta; suas estampas trazem imagens de mulheres de cabelos crespos, com turbantes, sempre enfatizando questões étnico-raciais; a empresária da marca acredita na importância da rede e aponta como seu produto fortalece as mulheres tanto em representatividade das estampas, quanto para geração de renda (SANTOS, 2019).

Outra empresária atuante é a idealizadora da marca Tica pelica, que corrobora com a ideia da rede, afirmando que esta tem um importante trabalho de valorização da mulher negra com talento, mas que não tem oportunidade; segundo ela, por meio do Kilofé foi possível que criassem o "Kitanda", que se trata de uma feira de arte, moda e cultura, realizada a cada dois meses que reúne expositores da rede Kilofé (SANTOS, 2019).

O evento São Paulo Fashion Week apresentou, em 2016, o desfile da marca Laboratório fantasma, criada pelo Rapper Emicida e seu irmão Evandro Fióti (Figura 1), encerrando o segundo dia de desfiles. Trouxe a mensagem de representatividade para o evento, por meio de uma coleção que contou com um casting rico em diversidade e mixou elementos orientais a estética africana (SANTOS, 2016).

\footnotetext{
${ }^{3}$ Empresas que utilizam o design para promover um consumo fast (rápido), nas quais "a velocidade de resposta ao mercado é considerada a verdadeira alavanca competitiva; os custos baixos dos seus produtos são obtidos principalmente pela exploração de seus fornecedores, aos quais impõem preços e condições de entrega que levam, inevitavelmente, á exploração de mão-de-obra" (CIETTA, 2010, p. 19).
} 
Figura 1- Desfile Laboratório fantasma para a São Paulo Fashion Week em 2016.

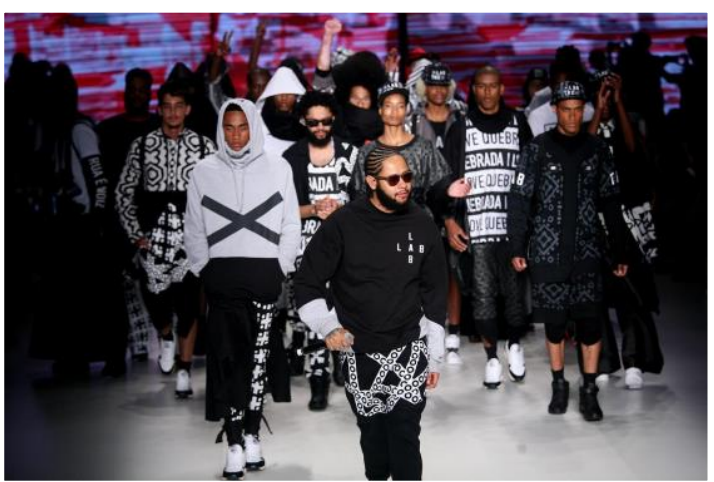

Fonte: Santos (2016).

Segundo Santos (2016, não paginado), Emicida deseja ressignificar conceitos por meio das roupas e diz que "[...] quando essa mudança te toca, todo seu universo é contaminado e você passa observar as coisas de maneira diferente". A marca Laboratório fantasma é uma ramificação de um projeto mais amplo, sendo também uma $h u b^{4}$ de entretenimento, que possui gravadora, editora, produtora de eventos e marca de streetwear; deste modo, seu site apresenta vários projetos com diferentes artistas, a hub existe desde 2009 com o propósito de "transformar a realidade do mercado, da música e da moda, colocando a cultura das ruas como protagonista" (LABFANTASMA, 2020, não paginado). Outro ponto importante que colaborou para a popularidade da Lab, segundo Casa Nova (2016), é a questão da utilização das tecnologias e das redes sociais, pois foi um fenômeno que se potencializou por meio dessas redes, de modo a ser explanado também nas letras do rapper com frases como: "a rua é nóiz", "a rede é nóiz" - tais afirmações dos artistas evidenciam a valorização da formação de redes com entre os "seus".

\footnotetext{
${ }^{4}$ Hubs de Inovação são iniciativas voltadas para a geração de negócios principalmente entre startups e grandes empresas, propícios para o encontro de pessoas que interagem, criam, empreendem, trabalham e inovam juntas, em rede; ajudam no desenvolvimento de empresas de base tecnológica com alto potencial de crescimento (NEOVENTURES.GLOBAL, 2020, não paginado).
} 
Corroborando com a ideia de formar redes, em entrevista para Santos (2019), Isaac Silva (estilista baiano) menciona a preocupação de pessoas negras se unirem e ainda faz um comparativo com o caso da religião Umbanda:

[...] este novo segmento de moda tem futuro e está crescendo, os empreendedores negros deste segmento precisam se unir, pois daqui a pouco serão os empreendedores brancos e endinheirados que irão desenvolver produtos de Moda Afro-Brasileira, assim como aconteceu com a invenção a religião Umbanda - os brancos desqualificaram Candomblé por ser uma religião de negros e o que vemos hoje, pessoas brancas no comando da Umbanda (SILVA apud SANTOS, 2019, p. 47).

Isaac Silva (figura 2) é um reconhecido estilista Baiano de moda Afro-brasileira, que enfrentou preconceito ao decidir seguir a carreira da moda e lançou sua marca em 2015, com o propósito de realizar o sonho de fazer roupas para que mulheres negras se sintam representadas (SANTOS, 2019). Pode-se dizer que Silva tornou-se empresário de moda por "acaso", fruto de suas experiências interpeladas pela raça e pela sexualidade: trabalhava em confecções no Bom Retiro, mas seus antigos patrões o deixavam sempre no balcão, e mesmo quando alcançou um espaço como estilista, ainda sim ganhava metade da remuneração dos estilistas brancos; isso devido à sua cor de pele e sua condição sexual (Gay), como salienta Santos (2019).

Assim, diante das situações vivenciadas e pela necessidade de buscar autonomia de expressão e maior visibilidade, o estilista resolveu empreender e seguir então a carreira de moda como empresário, fato que valida a preocupação mencionada anteriormente pela ASN (2020), sobre o motivo pelo qual empreendedores negros empreendem.

Figura 2 - Isaac Silva.

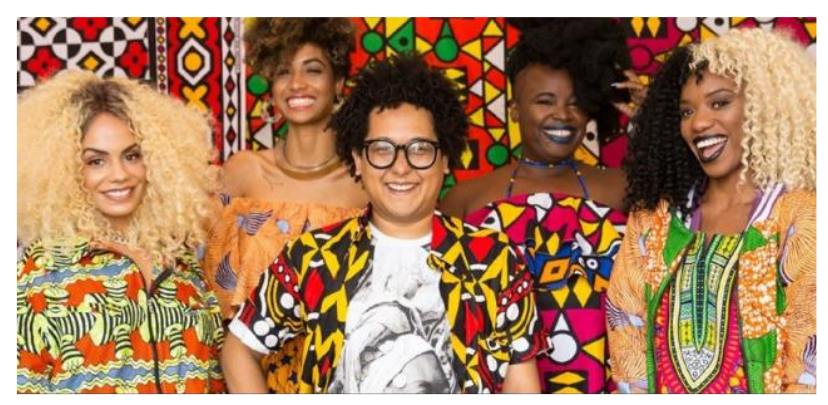

Fonte: Vilar (2019).

Para o estilista mencionado, a moda Afro-brasileira é a exaltação da ancestralidade brasileira, mostra o reencontro com as raízes e reverencia a cultura africana (SILVA apud SANTOS, 
2019, p. 46). Em sua última coleção "Jacira, flores para iemanjá", faz uma homenagem à sua tia-avó (Jacira) e lemanjá. A relação com sua tia está intrinsicamente relacionada com a fé do estilista, e a coleção retrata as flores que a tia o ensinou a oferecer para a orixá. Assim, esta coleção com referência de estética afro-religiosa trouxe o conforto e praticidade exigidos no momento pandêmico da Covid-19 (L'OFFICIEL, 2020, não paginado), propondo tecidos de malha, algodão e cetim tecnológico; a cartela de cores é marcada por branco e tons de azuis, somados à estamparia colorida da artista Jaqueline Paz, que utilizou a técnica do carimbo para as flores à lemanjá.

Além disso, a referida coleção valoriza a desconstrução de gêneros, rompendo assim com modelos binários, sendo pensada para vestir todos os tipos de corpos, independente do gênero. A marca apresenta nas mídias sociais vídeos com duas histórias sobre lemanjá, contadas pela militante negra e mulher trans Aretha Sadic (L'OFFICIEL, 2020, não paginado). Desta forma, é possível destacar que a marca do estilista carrega elementos de estéticas afro-religiosas, que, por sua vez, resgatam a ancestralidade negra.

Outra notável estilista brasileira que procura romper com modelos hegemônicos do sistema social e da moda é Carol Barreto - mulher negra, feminista, designer de moda e pesquisadora atuante na área acadêmica na Bahia, buscando enquanto designer a expressão de seu "lugar de fala" em criações de moda, transformando as passarelas e fotografias em um espaço de militância (BARRETO, 2015). Para isso, a estilista busca interlocução com ativistas que, assim como ela, propõem com a linguagem do corpo questionar padrões socioculturalmente cristalizados e legitimados, apontando para o fato de que cria roupas tentando expressar visualidades que não estão disponíveis no mercado (Figura 3).

Figura 3 - Carol Barreto na 4ạ edição da Black Fashion Week (Paris).

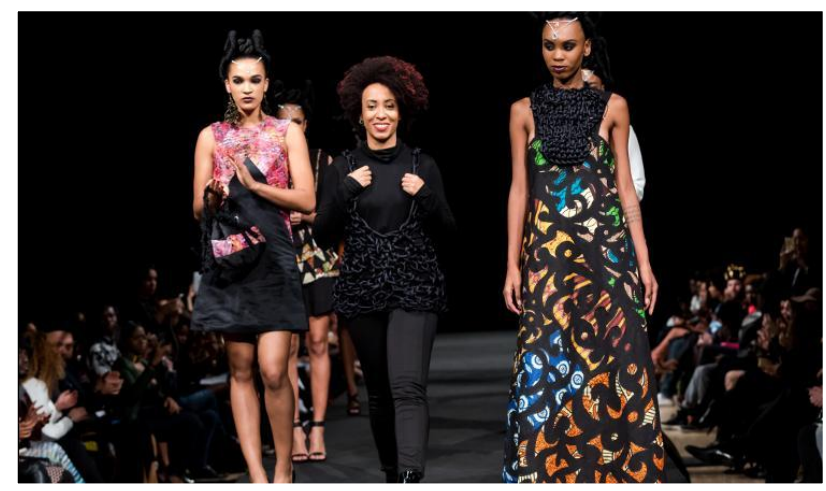

Fonte: Afropunk (2016). 
A designer de moda traz para o processo criativo de suas coleções as interlocuções do ativismo político.

Busco compreender as interlocuções entre ativismo político e os processos criativos no âmbito da moda, desde a aparência individual de membrxs de grupos negrxs e LGBTs, como as mulheres transexuais e negras, bem como refletir acerca dos meus processos criativos na elaboração de coleções de moda que compõem a minha trajetória como estilista, buscando analisar como se articulam os discursos políticos e estéticos com a minha trajetória acadêmica como docente na área dos Estudos Feministas e de Gênero e no Design de Moda (BARRETO, 2015, p. 144).

A autora observa que poucas mulheres negras atuam no campo prático da moda e acadêmico simultaneamente, como ela; desta forma, busca "ratificar a importância do registro e da instrumentalização desses discursos como maneira também de visibilizar vozes e fazeres sempre tidos como subalternos" (BARRETO, 2015, p. 145). A pesquisadora vem desenvolvendo o conceito de ModAtivismo, intrinsecamente relacionado ao seu lugar como mulher negra e, assim, revela para o site Fashion Revolution ${ }^{5}$ :

\begin{abstract}
ModAtivismo nasce a partir do reconhecimento e da problematização do meu lugar de existência e por meio da constatação de que para nós mulheres negras, a aparência, a corporalidade, os aspectos intangíveis da moda e sua materialidade vestimentar ou estética, são planos de expressão discursiva e também esfera de materialização dos marcadores sociais das diferenças, nos posicionando numa escala subalternizada dentre as hierarquias sociais (BARRETO, 2020, não paginado).
\end{abstract}

Percebe-se o quanto a moda Afro-brasileira é discursivamente potente no seu rico papel atual de problematizar o lugar de existência do corpo negro, a partir do qual cada marca apresentada constrói suas próprias singularidades; contudo, por mais que essas marcas ativistas tenham suas especificidades, existe uma intersecção entre elas, pois todas têm um apelo político pautado na ressignificação de conceitos, no resgate da ancestralidade que se expressa em roupas, ou no caso da Lab que atua da ressignificação do hip-hop - também consiste em uma cultura negra e na cultura de rua.

Nota-se também a importância da formação em redes de apoio e pertencimento, bem como compreende-se que tais marcas apresentam contestam padrões estabelecidos pela cultura branca europeia e, de alguma forma, se orientam fora dos caminhos pré-estabelecidos historicamente

\footnotetext{
${ }^{5}$ Fashion Revolution é um movimento que acredita principalmente no poder de transformação positiva da moda e tem como principais objetivos conscientizar sobre os impactos socioambientais do setor, celebrar as pessoas por trás das roupas, incentivar a transparência e fomentar a sustentabilidade (FASHION REVOLUTION BRAZIL, 2021, não paginado).
} 
para seus protagonistas e públicos-alvo. São marcas que reivindicam seu espaço no sistema social, político e econômico, que protestam e conquistam engajamento midiático, ressignificando gradativamente o sistema da moda dominante.

Essas marcas apresentadas ajudam a configurar um panorama favorável à arte de (re)existir, contribuindo assim para consolidar o diálogo entre moda e engajamento estético-político, em favor das identidades negras no cenário nacional. Nesse sentido, torna-se fundamental na pesquisa o aprofundamento desta arte com a marca catarinense Zkaya, cujas informações foram coletadas por meio de entrevista com sua proprietária e idealizadora.

\section{ZKAYA E A ARTE DE (RE)EXISTIR}

Zkaya é uma marca Afro-brasileira, com sede na cidade de Criciúma (SC), criada por Laís Costa, ou melhor, Laís Zkaya como tem se pronunciado. Tendo o propósito de incentivar a arte de (re)existir, a história da marca está intrinsecamente relacionada com sua idealizadora, carregando inclusive uma vertente política que se faz presente em suas redes sociais - que apresenta a própria imagem de Laís Zkaya. Atualmente, a marca possui um mix de produtos vasto: calçados de vários modelos, bonés, brincos, bolsas, colares, boneca, cintos, turbante e maiôs/body.

A empresária da marca conta que, para ela, a Zkaya inicia ainda na sua juventude, no ano de 2003, com venda de brincos em miçangas; porém, entre os anos de 2004 e 2007, devido ao ensino médio e diversas atividades que a mesma desenvolvia, a produção foi suspensa. Após este período, entre os anos de 2008 e 2009 ainda com o nome Zakii ${ }^{6}$ (primeiro nome da marca), ela volta a produzir bijuterias - uma habilidade conhecida pela empreendedora, mas renovada com sementes, garrafas pet e com fundos de latinha de cerveja/refrigerante, esse último modelo está na marca até hoje, em poucas quantidades devido a sua produtividade. Ainda no mesmo período a empresária descobre habilidades para desenvolvimento de bolsas e assim insere este produto na Zakii Contudo, Laís Zkaya despertou interesse por moda e, nesse momento, abandonou o curso de

\footnotetext{
${ }^{6}$ Nome de origem africana que significa esperta, inteligente, e também “a proeza do leão" (COSTA, 2020).
} 
Marketing que fazia, inicia um curso na área da Moda - que, por sua vez, levou a empresária a trabalhar em outras empresas, "abandonando"” assim a marca Zakii.

Laís trabalhou em diversas empresas, em cargos diferentes, como assistente de estilista e no desenvolvimento de produto; assim como Isaac Silva, não tinha oportunidades como criadora. A empresária comenta sobre sua frustração com o mercado de moda dominante e o quanto isso a incomodava, pois não se sentia contemplada e esse mundo a cobrava um "glamour" que ela não sentia ser pertencente ao seu corpo (COSTA, 2020).

Entretanto, dentro da indústria da moda, com o auxílio de pessoas, Laís aprendeu a desenhar estampas, tornando possível dois projetos paralelos em 2015 na vida da empreendedora. Em 2015, já fora da indústria, ela começou a prestar serviço como designer para outras marcas; e também empreendeu na sua própria marca de camisetas (também com o nome Zakii). A Zakii, como marca de camisetas, durou pouco tempo, a empreendedora comenta que criou a marca porque precisava daquilo para fazer outras coisas e não porque se sentia realizada. Em 2016, com a crise econômica do país, boa parte dos clientes de design de estampa da empreendedora passaram a desenvolver sua estampa diretamente com os fornecedores de tecidos, o que era muito mais viável a partir daquele momento. Mais uma vez a designer precisava se reinventar, (re)xistir, passava por um momento também no qual precisava fazer algo que realmente fizesse sentido para ela, iniciando seu processo de reconhecimento como pessoa negra. (COSTA, 2020).

Então Laís começou a desenvolver estampas Afro-brasileiras exclusivas e aplicadas em brincos, algo que era acessível financeiramente naquele momento e que resgatava as questões que precisava abordar (COSTA, 2020). Com os brincos de estampas exclusivas, Laís se aventurou como ambulante nas praias de Florianópolis (SC), sendo um período difícil, mas que ao mesmo tempo garantiu a certeza de que era aquilo que ela desejava para si mesma: "não isso de vender na praia como ambulante, isso eu tinha certeza de que eu não queria, mas a certeza de que eu queria a Zakii para mim" (COSTA, 2020). Relata que foi um longo e difícil processo, que se sentia inferiorizada, principalmente porque tinha profissão e formação. Contudo, ao voltar para Criciúma (SC), retorna com uma nova proposta, modificando site, layouts e expondo em feiras.

\footnotetext{
7 Entre aspas, pois, ao longo e no contexto da entrevista, trata-se muito mais de uma parte do processo de autodescoberta e reconhecimento próprio do que um abandono.
} 
Em maio de 2017 Laís disse que teve um divisor de águas: "minha mãe me colocou contra a parede e disse, olha Laís do jeito que está não dá, você precisa voltar a trabalhar em uma empresa, porque não tá dando" (COSTA, 2020 - informação verbal). Na época morava com os pais e como tinham dívidas Laís pediu dois meses para sua mãe, pois se não desse certo, venderia tudo e faria qualquer coisa, menos trabalhar para o mercado de moda, pois o achava muito doloroso (COSTA, 2020).

A empresária conseguiu então que um fornecedor estampasse uma metragem pequena de tecido, sentou-se na máquina depois de anos e criou bolsas, postando as imagens nas redes sociais. Obteve nove encomendas e produziu treze bolsas; com o faturamento das vendas, participou de dois eventos importantes na construção da futura Kzaya: o Congresso de Pesquisadores Negros (COPENE) e uma edição do "Seminário Internacional Fazendo Gênero 11 \& Mundo de Mulheres", ambos eventos sediados na Universidade Federal de Santa Catarina (UFSC) em Florianópolis; foram muito lucrativos para a empresária, que por meio deles pagou parte de suas dívidas e conseguiu comprar mais tecidos, investindo assim no seu primeiro modelo de calçados (COSTA, 2020). A partir deste ponto, a Zakii começou a ter um avanço muito rápido, com um calendário de produção: julho bolsas, agosto calçados, setembro bonecas, outubro turbantes e então no final do ano de 2017 a marca já havia crescido consideravelmente; destaca-se que de todos os produtos comercializados (exceto sapatos e bonecas) eram produzidos pela própria empresária.

Prosseguindo com a próspera linha cronológica da marca, em maio de 2018 Laís saiu no site da revista Marie Claire ${ }^{8}$ por meio de uma série de entrevistas com mulheres negras e empreendedoras, realizada por Stephanie Ribeiro; em agosto do mesmo ano ela foi convidada para participar do programa "É de Casa", da emissora Rede Globo, para fazer o brinco com fundo de latinha (que ainda possui em seu mix de produtos); em setembro a empresária retorna ao programa para ensinar colares.

É importante salientar que no mês de agosto o espaço destinado para produção das peças (a garagem dos pais de Laís) não comportava mais o volume de trabalho, sendo então alugada uma casa próxima à casa dos pais para montar o ateliê e o showroom da Zkaya, inaugurado em outubro;

\footnotetext{
${ }^{8}$ Consultar em: https://revistamarieclaire.globo.com/Blogs/BlackGirlMagic/noticia/2018/05/negras-empreendedorascomo-ser-ambulante-na-praia-ajudou-lais-costa-empreender.html.
} 
no mês seguinte, Laís foi convidada para participar do programa "Catarinense como Você", da emissora de TV SBT, retornando ainda mais duas vezes ao programa "É de casa" (COSTA, 2020).

Em setembro de 2018 a marca muda de nome devido a problemas de registro. Laís conheceu por acaso uma amiga em um evento de mulheres negras - "por acaso não, porque nada é por acaso nessa vida" (COSTA, 2020) e, com a ajuda próxima, compreendeu que não valeria a pena brigar na justiça por esse nome, pois teria que batalhar contramarcas grandes e dificilmente ganharia, surgindo assim o nome Zkaya.

A origem deste nome vem de uma frase preferida da empresária: "quando tudo parece dar errado, acontecem coisas boas que nunca teriam acontecido se tudo tivesse dado certo" (COSTA, 2020); um amigo sugeriu que esta frase se resumia em "fé", então Laís pesquisou símbolos adinkra para fé, mas não gostou do símbolo; entretanto, a pesquisa realizada a levou a encontrar o símbolo Aya, que representa resistência e perseverança; então, com a amiga próxima, Laís decidiu por Zkaya, que era também uma forma de não abandonar o nome Zakii que sempre fez muito sentido para a marca. Em seguida, foi realizado o registro do nome Zkaya (Figura 04).

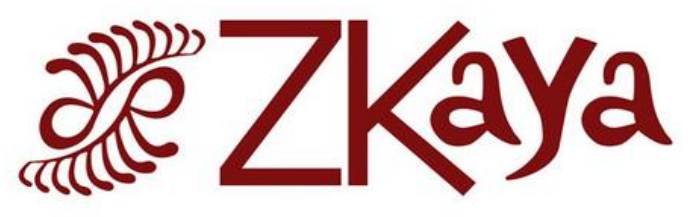

Fonte: Zkaya (2021).

As letras "ZK" foram desenhadas em linhas retas, representando o masculino; e "aya" em linhas sinuosas, representando o feminino; o "Y" da logo é maior e abraça as duas letras "a", de modo a representar o abraço feminino. Portanto, a logo surge da junção do feminino com o masculino. Laís deixa claro que não é uma coisa e nem outra, mas sim a junção; tal questão da junção dos gêneros no nome sugere um apelo antissexista que fica evidente também no site da marca, cujas peças são separadas pelo produto e não por gêneros; já o símbolo é derivado do símbolo de aya em Adinkra, porém estilizado de modo que sugira um "Z". 
Laís tinha certa preocupação das pessoas confundirem achando que a marca era apenas para pessoas negras, afirmando que não se trata disso; desta maneira, ela explica que, quando ela traz o slogan "a arte de (re)sistir", acredita que:

[...] é a possibilidade que a gente tem todos os dias de se reinventar, de existir de uma forma diferente, então é um (re)existir na sua essência. Então quando a Zkaya vem com essa nova identidade, com essa nova leitura é para que a gente possa renascer e renascer sempre, que nossos produtos possam auxiliar nesse renascimento (COSTA, 2020).

Outra experiência ímpar, segundo Laís, ocorreu em dezembro de 2019: sua participação na Feira Preta de São Paulo - a maior feira Afro da América Latina. Na ocasião ela teve a certeza de que seu produto era diferenciado, sendo o evento um importante validador para a mesma. Laís esteve acompanhada de seu primo e irmão e para ela foi muito gratificante conseguir demonstrar para a família todo o valor do seu trabalho, testemunhando o desejo que o público tinha sobre seu produto. Contudo, no início de 2020 o país vive as consequências da pandemia Covid-19, exigindo novamente da empresária a reinvenção; não foi um processo fácil, pois pensou em desistir, mas o grande incentivo da mãe a motivou, encorajando-a a não desistir, argumentando que Laís já havia trilhado um caminho sem volta (COSTA, 2020).

Destaca-se que todas as estampas da Zkaya são exclusivas e criadas pela própria empresária, com motivos africanos em padronagens diversas, em cores para todos os gostos. Assim, as estampas da marca resgatam uma pluralidade estética africana que o sistema dominante tenta invisibilizar e/ou marginalizar desde o período colonial. Para além das padronagens africanas, que portanto resgatam e ressignificam a cultura Afro-brasileira, a marca também se destaca na modelagem de seus produtos; os calçados oferecem a numeração do tamanho 33 ao 44, certamente difícil de se encontrar no sistema dominante de moda; e os bonés são desenvolvidos especificamente para cabelos crespos (Figura 5), contestando os padrões estéticos e culturais préestabelecidos por homens brancos europeus. Desta forma, propõe a articulação de novos caminhos, como sugerido pelo design ativista de Bush (2017). 
Figura 5 - Bonés para cabelos crespos e cacheados.

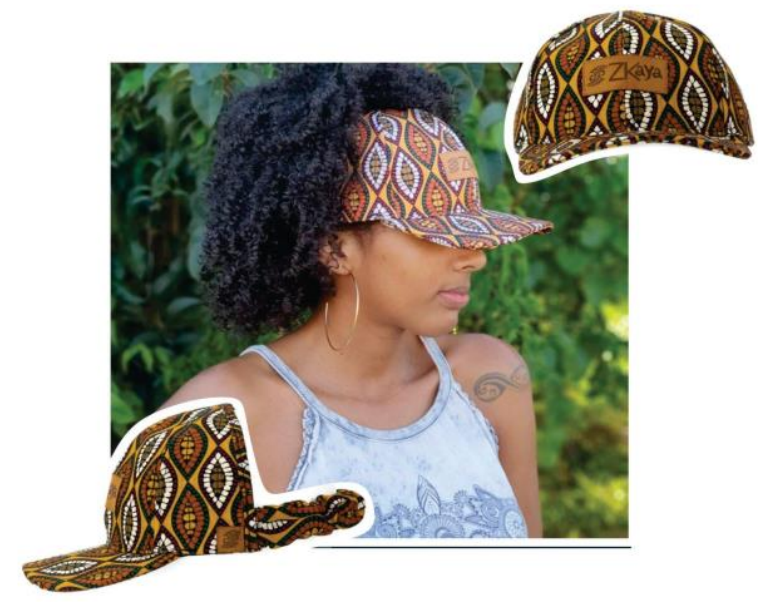

Fonte: Zkaya (2021)

Laís não reproduz o ativismo somente por meio da estética Afro-brasileira de suas peças, mas tenta ao máximo trazer outras práticas. Dentre elas, estão as voltadas para o apelo ambiental, como o upcyle dos brincos de latinha, a reciclagem das caixas dos seus produtos e bonecas confeccionadas com reaproveitamento dos seus tecidos. Além disso, Laís utiliza as redes sociais ${ }^{9}$ como forma de engajamento político, levando para seu público parcerias colaborativas e divulgando pintores e artistas pretos, restaurantes de comida típica africana e ainda lives ${ }^{10}$ com temas que atravessam a marca - como o racismo. Recentemente, lançou o Uakani, um podcast ${ }^{11}$ formado pela empresária e outros apresentadores com diferentes profissões, diferentes corpos e subjetividades, mas com uma intersecção em comum: todos negros. O grupo se reúne e discute questões que atravessam seus corpos, assim como apresenta na descrição do podcast:

\footnotetext{
${ }^{9}$ Acessar: https://instagram.com/zkayaoficial.

10 “[...] A live é um recurso do "Instagram Stories” que permite a gravação e transmissão de vídeos ao vivo" (NEIPATEL, 2021, não paginado).

11 [...] considera podcast como derivado da junção de dois termos: broadcasting (radiodifusão) e iPod, dispositivo de áudio da marca Apple que executa arquivos de áudio no formato MP3. Em linhas gerais, o podcast é um arquivo de áudio disponibilizado na internet para download gratuito [...] (LENHARO; CRISTOVÃO, 2016, não paginado)
} 
Pensar Uakani é pensar que é tempo de aquilombar-se, tempo de cuidado, de conexão conosco e com nossa ancestralidade, é tempo de trocar conhecimento, afeto, saberes e dores, é tempo de resistir e acreditar em um futuro melhor. Somos pessoas de lugares, histórias e profissões diversas, mas também somos iguais em muitas dores, experiências e vivencias. Aqui a vida será pautada, não há limites ao que a gente tem a dizer, porque nós somos o podcast que tem muito a dizer (UAKANI, 2020, não paginado).

Em um episódio do Uakani (2020) dedicado a responder se as marcas podem ser neutras em posicionamentos políticos, os apresentadores ressaltam que "neutro é detergente" (UAKANI, 2020, não paginado); reforçam ainda que o ato de se posicionar politicamente não se resume a publicitar corpos negros, mas optar por práticas mais efetivas - tais como empregar mais negros dentro de empresas bem estabelecidas, inclusive em cargos "superiores". Percebe-se que a marca se encontra em um momento de expansão, com maior consciência de sua responsabilidade social.

Deste modo, a Zkaya demonstra um crescente comprometimento com a ressignificação da moda no Brasil, em sintonia com as marcas mencionadas no tópico anterior. A escolha estéticopolítica da utilização de padronagens e modelagens afrocentralizadas valoriza identidades negras, bem como a ampliação de sua exposição midiática dos últimos anos são sintomas de seu lugar como referência de empreendedorismo negro em Santa Catarina.

\section{CONSIDERAÇÕES FINAIS}

O objetivo do artigo foi identificar ações de engajamento estético-político da marca catarinense Zkaya voltadas para a valorização das subjetividades de identidades negras, no contexto do ativismo e da moda Afro-brasileira no cenário contemporâneo. Nesse sentido, o caminho teórico traçado mostrou-se bastante válido para a compreensão de como operaram historicamente as estruturas hegemônicas do poder branco sobre o corpo [negro] e o papel de docilização protagonizado pela moda em paralelo com estratégias cristalizadas de biopolítica, sobretudo no século XIX.

Entretanto, o panorama apresentado por marcas de moda Afro-brasileiras voltadas para a valorização de identidades negras do cenário nacional revelou o quanto estas resistem ao sistema dominante no século XXI. Em alguns casos, a moda mostra-se território de contestações ativistas - 
sobretudo do ativismo negro aqui em pauta, evidente nas ações da rede Kilefé, da LAB de Emidica, de Isaac Silva, de Carol Barreto e da Zkaya, no contexto catarinense.

Compreende-se também que tais marcas se utilizam de ferramentas bastante semelhantes: Kilefé é uma rede, a LAB uma hub, então ambas primam pela união de pessoas negras para se fortalecerem, da mesma forma que Laís Zkaya traz à tona a necessidade de aquilombar-se por meio de inúmeras parcerias. Foi possível perceber que tanto Isaac Silva quanto Laís Zkaya se tornaram empreendedores pela hostilidade do mundo da moda perante a seus corpos, fato que valida os dados apresentados pelo ASN, que por sua vez "desromantiza" as reais condições socioculturais e econômicas pelas quais negros empreendem no país.

A ressignificação estética presente em todas as marcas analisadas revelou-se como um notável aspecto em comum entre elas, que buscam um resgate da ancestralidade ressignificando conceitos, processos e produtos - embora não necessariamente da mesma maneira, pois cada marca construiu uma identidade própria, uma vez que a identidade Afro-brasileira é diversa. Nesse sentido, a Zkaya se consolidou com estampas de motivos africanos e a LAB de Emicida com a estética do Hip-Hop e das ruas. Outro ponto que valida o ativismo na moda dessas marcas, no que diz respeito à valorização das subjetividades negras, é o seu engajamento midiático, contribuindo para agenciar maior visibilidade no cenário contemporâneo do atual século, como protagonizam as vozes e os lugares de LAB, Isaac Silva e a Zkaya.

Assim, é incontestável que essas marcas de moda Afro-brasileiras estejam trabalhando em favor de práticas efetivas de engajamento estético-político antirracistas, procurando transcender os limites para elas impostos dentro de um sistema "dominante". Embora façam isso dentro de suas possibilidades, pois o racismo se insere historicamente em uma estrutura social hegemônica branca ainda bastante cristalizada. Os resultados obtidos até o momento revelaram que as marcas em questão transformam articuladamente sua diferença, sua exclusão e sua "anormalidade" em potencialidades, tornando-se atores importantes para a ressignificação da moda e valorização das subjetividades das identidades negras. 


\section{REFERÊNCIAS}

AIRES, A. B. De gorda a plus size: a moda do tamanho grande. São Paulo: Estação das Letras e Cores, 2019.

ASN. Agência Sebrae de Notícias. Afroempreendedorismo cresce atuação no Brasil: No mês de comemoração do Dia Nacional da Cociencia Negra, o empreendedorismo negro também representa a luta por igualdade, respeito e representatividade. 2020. Sebrae. Disponpivel em: https://www.sebrae.com.br/sites/asn/uf/NA/afroempreendedorismo-cresce-atuacao-nobrasil,54994b31ad5e5710VgnVCM1000004c00210aRCRD. Acesso em: 24 nov. 2020.

BARRETO, C. Moda e feminismo. Revista Feminismo, Bahia, v. 3, n. 1, p. 135-146, abr. 2015. disponível em:

https://cienciasmedicasbiologicas.ufba.br/index.php/feminismos/article/viewFile/30092/17808. Acesso em: 24 nov. 2020.

BARRETO, C. ModAtivismo como prática insurgente para pensar o Dia Internacional da Mulher negra. 2020. Fashion Revlution. Disponpivel em: https://www.fashionrevolution.org/brazilblog/modativismo-como-pratica-insurgente-para-pensar-o-dia-internacional-da-mulher-negra/. Acesso em: 24 de nov. 2020.

CASA NOVA, J, O. "A rede é nóiz: a amplificação do discurso do rap a partir do uso da tecnologia e das redes sociais na trajetória do rapper Emicida". XXXIX CONGRESSO BRASILEIRO DE CIÊNCIAS DA COMUNICAÇÃO, 39., 2016, São Paulo . Anais eletrônicos [...]. São Paulo: INTECOM, 2016.

Disponível em: https://portalintercom.org.br/anais/nacional2016/resumos/R11-1729-1.pdf. Acesso em: 21 nov. 2020.

CIETTA, E. A revolução do fast fashion: estratégias e modelos organizados para competir nas indústrias híbridas. São Paulo: Estação das Letras e Cores, 2010. Disponível em:

https://www.researchgate.net/publication/313619476_A_revolucao_do_fast-fashion__estrategias_e_modelos_organizativos_para_competir_nas_industrias_hibridas. Acesso em: 19 fev. 2021

CRANE, D. A moda e seu papel social: classe, gênero e identidade das roupas. São Paulo: Editora Senac, 2006.

FASHION revolution brazil. [S. I.: s. n.], 2021. Disponível em: https://www.fashionrevolution.org/south-america/brazil/. Acesso em: 19 fev. 2021.

FOUCAULT, M. História da sexualidade I: A vontade de saber. Rio de Janeiro: Edições Graal, 1988.

HALL, S. Identités et cultures 2:Politiques des différences. Paris: Éditions Amsterdam, 2013. 
KATZ, H. Para ser contemporâneo da biopolítica: corpo, moda, trevas e luz. In: MESQUITA, C.; CASTILHO, K. Corpo, moda e ética: pistas para uma reflexão de valores. São Paulo: Estação das Letras e Cores, 2012.

LENHARO, R. I.; CRISTOVÃO, V. L. L. PODCAST, Participação social e desenvolvimento. Educação em Revista, Belo Horizonte, v. 32, n. 1, jan./mar, 2016. Disponível em: https://www.scielo.br/scielo.php?pid=S0102-46982016000100307\&script=sci_arttext\&tlng=pt. Acesso em:07 mar. 2021

LIPOVETSKY, G. O império do efêmero: a moda e seu destino nas sociedades modernas. São Paulo: Companhia das Letras, 1987.

LIVE no instagram: o que é, como fazer uma boa live e recursos. Neilpatel, 2021. Disponível em: https://neilpatel.com/br/blog/live-no-instagram/. Acesso em: 19 fev. 2021

MESQUITA, C.; CASTILHO, K. Corpo, moda e ética: pistas para uma reflexão de valores. São Paulo: Estação das Letras e Cores, 2012.

MICHETTI, M. Panorama histórico da moda "ocidental": planetarização ou universalização? In: MICHETTI, M. Moda Brasileira e Mundialização: mercado mundial e trocas simbólicas. Tese (Doutorado em Sociologia) - Universidade Estadual de Campinas, Campinas, 2012. p.37-99. Disponível em: http://repositorio.unicamp.br/bitstream/REPOSIP/280865/1/Michetti_Miqueli_D.pdf. Acesso em: 19 fev. 2021.

NOVELLI. D. A branquitude em Vogue (Paris E Brasil): Imagens da violência simbólica no século XXI. 2014. 345f. Tese (Doutorado Interdisciplinar em Ciências Humanas). Universidade Federal de Santa Catarina. Santa Catarina, Florianópolis, 2014. Disponível em: https://repositorio.ufsc.br/xmlui/handle/123456789/123183. Acesso em: 19 fev. 2021.

SANTOS, M. do C. P. Moda Afro-brasileira, design e resistência: ao vestir como ação política. Dissertação (Mestrado em Têxtil e Moda) - Escola de Artes, Ciências e Humanidades de São Paulo. São Paulo, p. 159. 2019. Disponível em: https://www.teses.usp.br/teses/disponiveis/100/100133/tde-06122019182505/publico/Moda_Afro_Brasileira_MCPS.pdf. Acesso em: 24 nov. 2020.

SANTOS, G. Lab injeta representatividade na passarela do SPFW: Empreitada fashionista de Emicida com seu irmão Evandro Fióti foi destaque do segundo dia da semana de moda pelo casting e moda inclusivos. Vogue. Rio de Janeiro: Globo, 2016. Disponível em:

https://vogue.globo.com/moda/moda-news/noticia/2016/10/lab-injeta-representatividade-napassarela-do-spfw.html. Acesso em: 24 nov. 2020 
SIS. Sistema de Inteligência Setorial, Moda Africana no Brasil. Boletim de Tendências: SEBRAE-SC. fev. 2016. Disponível em: https://atendimento.sebrae-sc.com.br/inteligencia/boletim-detendencia/moda-africana-no-brasil. Acesso em: 19 fev, 2021

UAKANI. Podcast. Disponível em: https://open.spotify.com/show/3n3JxCejWUk7V4meLhMHkU?si=ojp4uVgJSRWFXD0ELJCSMw. Acesso em: 25 nov. 2020

VILAR, M. Estilista baiano Isaac Silva faz estreia no SPFW com desfile "acredite no seu axé": Foco desra temporada do São Paulo Fashion Week é em sustentabilidade e ativismo. 2019. Disponível em: https://www.metro1.com.br/noticias/cultura/81480,estilista-baiano-isaac-silva-faz-estreia-nospfw-com-desfile-acredite-no-seu-axe. Acesso em: 24 nov. 2020

HUBS de inovação: O que são e como podem gerar resultados para as grandes empresas. neoventures.global, [S. I.: s. n.], 11, ago. 2020. Disponível em: https://neoventures.global/pt/2020/08/11/hubs-de-inovacao-o-que-sao-e-como-podem-gerarresultados-para-as-grandes-empresas/. Acesso em: 15 dez. 2020.

ZKAYA, Moda Afro-brasileira. [S. I.: s. n.], 2021. Disponível em: https://www.zkaya.com.br/. Acesso em: 19 fev. 2021. 